\title{
Strategy for tram noise reduction
}

\author{
Eva Panulinová ${ }^{1, *}$ and Slávka Harabinová ${ }^{2}$ \\ ${ }^{1,2}$ Technical University of Košice, Faculty of Civil Engineering, \\ Institute of Structural Engineering, Slovakia
}

\begin{abstract}
When there are many sources it is important to determine the sound power and directivity of each to determine their relative contributions to the noise problem. Any noise problem may be described in terms of a source, a transmission path and a receiver and noise control may take the form of altering any one or all of these elements. The aim of this paper is to suggest ways of reducing tram noise by technical and technological means.
\end{abstract}

\section{Introduction}

Noise is sound which is unwelcome but the annoyingness depends on the individual. Noise is phenomenon, contaminating the environment. Noise from traffic specifically from tram traffic is unwanted sound and is among the most pervasive pollutants today. The problem with noise is not only that it is unwanted, but also that it negatively affects human health and well-being. For implementing the sustainability goals formulated in the EC 2011 Transport White Paper and the Greening of Transport package, the environmental impact of tramway operations needs to be minimised.

The aim of this paper is to suggest ways of reducing noise from trams by technical and technological means.

\section{Sources of tramway noise}

Rail noise is sound emissions arising from the operation of trains and trams. There are a wide variety of sources and causes of rail noise, such as wagons braking, squeal noise in curves, vibration from rail corrugation and out-of-round wheels, etc.

Many studies and publications exist concerning sources of rail noise. The Working Group Railway Noise of the European Commission published its Position Paper on the European strategies and priorities for railway noise abatement in 2003 [1]. The International Union of Railways (UIC) published its "Environmental Noise Directive Development of Action Plans for Railways" in April 2008 [2]. Both studies identify three dominant sources for railway noise:

- Rolling noise.

- Power equipment noise.

- Aerodynamic noise.

*Corresponding author: eva.panulinova@tuke.sk 
Train speed is a major influence parameter for noise emission. Aerodynamic noise is important for high-speed trains. Tramways as a kind of urban railway transport, operating in densely populated areas. Trams run therefore speeds up to $50 \mathrm{~km} / \mathrm{h}$. At medium speed the dominant source is rolling noise [3]. The rolling noise depends strongly on the surface condition (roughness) of wheels and rails. According [4] the noise source analysis was indicated that most sources are located on the lower part of the vehicles. The area centre is located either at 0.5 - 1 meter height for ground.

The tram is often seen as environmentally friendly, namely non-polluting and silent. However complaints from residents living along the lines prove that it may sometimes lead to annoyance.

\section{Effects of noise}

WHO published in 2011 a study about the burdens of disease from environmental noise [4]. One result of the study is that, about 1 million years of healthy life are lost in the EU every year due to noise reasons.

While the human ear can perceive an increase in sound volume as sound energy increases, the relationship is logarithmic. If two identical $10 \mathrm{~dB}$ noise sources are placed together, the perceived increase is not a doubling of the volume but rather a $3 \mathrm{~dB}$ increase. As such, a sound level increase from $45 \mathrm{~dB}$ to $55 \mathrm{~dB}$ may not look like much on paper, but it represents a ten-fold increase in sound energy and its impact on human health. Humans are usually able to sense a change of $3 \mathrm{~dB}$ in sound level, which corresponds to a limit of sensitivity. Measures to reduce noise levels by less than $3 \mathrm{~dB}$ would, by themselves, be of no real value. Sound can also be transmitted as vibration through the ground and directly into the body, and this is also a form of noise pollution $[5,11,12]$.

The faintest audible sound is at $0 \mathrm{~dB}$; the pain threshold is about $120 \mathrm{~dB}$. If it is louder than $120 \mathrm{~dB}$, there is a risk of injury. At a detonated blast of $150 \mathrm{~dB}$ the eardrum can rupture. Noise exposure during sleep such as night flight noise is regarded as particularly critical. So night noise causes health hazards already at individual levels below $45 \mathrm{~dB}$, if the difference between the individual level and the background noise is more than $3 \mathrm{~dB}$. Noise above $55 \mathrm{~dB}$ is considered as noise pollution. If noise above this level lasts for an extended period of time, the efficiency and well-being of a person will be reduced. Noise in the range 65 to $75 \mathrm{~dB}$ causes stress to the body. This can lead to arterial hypertension (high blood pressure), cardiovascular disease and myocardial infarction (heart attack). Noise can also provide for a reduction of gastric secretion and be the cause of stomach ulcers [4-6, 9].

\section{Analysis of noise regulation possibilities}

One of the possibilities to place the tramway is its location in the common corridor with road traffic. This is so even in most of the localities in Kosice. The various types of permanent way in the city of Kosice are presented on photos in Fig. 1.

When we analyze the acoustic conditions it is important to identify the main source of the noise and to determine the dominant producer of noise. It is necessary, to be effective measures for noise reduction $[13,14]$.

Decibels are logarithmic "units", they may not be added linearly like other figures. In most cases we will add uncorrelated signals as noise. If a sound source creates a sound level of $L_{1}=60 \mathrm{~dB}$ and another source with $L_{2}=60 \mathrm{~dB}$ is added, then it is not the level of $120 \mathrm{~dB}$, but gives an incoherent (noncoherent) summing of the signal level of $63 \mathrm{~dB}$. If both values are equal, it is easy [4]. 
Adding of two incoherent (noncoherent) sound pressure levels we must use the relationship:

$$
L=10 \log \left(10^{L_{1} / 10}+10^{L_{2} / 10}\right) \mathrm{dB}
$$
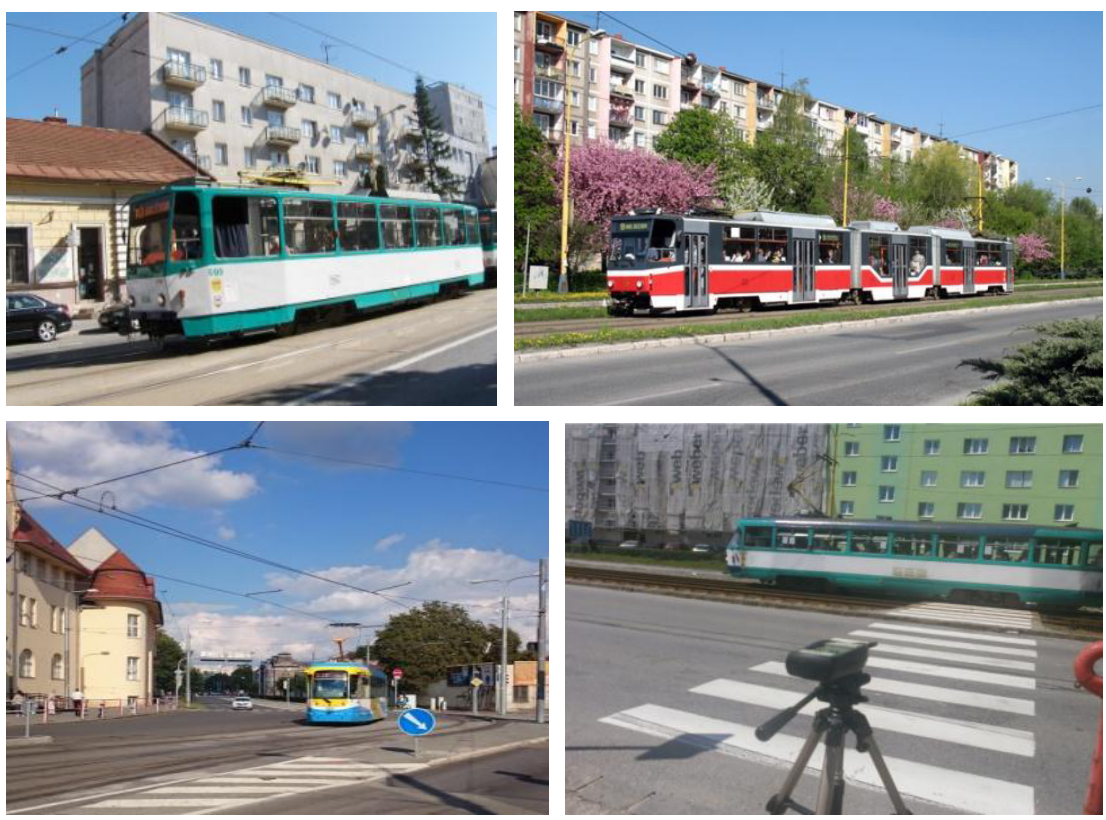

Fig. 1. Photos of tram permanent way located in the common corridor with road traffic in the city of Kosice.

\subsection{Example}

The analysis of a noise event caused by a tram travelling along the road in Kosice, which is one of the busiest tram lines are operated by three regular and one irregular line. It is a densely built-up area where prevail residential houses. Tramway track is lined on both sides by four-lane road. The tram rails are located on concrete sleepers in the ballast (a classical open permanent way). The dominant sound source in a busy location, as published in the paper $[7,8]$ is a tram transport. Measurements were detected value of the equivalent noise level $L_{1}=57 \mathrm{~dB}$ (at night without trams) in the monitored area. Especially noise from trams $L_{2}=L_{\text {Aeq, } 1 h}$ (A-weighted equivalent sound level in $\mathrm{dB}$ measured over a period of 1 hour) was determined by theoretical calculations by Liberko [10].

As has been already shown in:

$$
\begin{gathered}
L_{2}=10 \log X+40=10 \log 534+40=67.3 \mathrm{~dB} \\
X=44.5 \cdot F_{5} \cdot m=44.5 \cdot 0.50 \cdot 24=534
\end{gathered}
$$

where:

- $F_{5}$ factor depends on the average speed of the tram, for the classical open permanent way and speed of $30 \mathrm{~km} / \mathrm{h}$ is valid $F_{5}=0.50$.

- $m$ is the number of trams that pass the given section of the tramway per one hour. Value was found in the early night time $m=28$ vehicles per hour. 
The determination of the equivalent level of tramway noise is given by (2), $L_{2}=67.3 \mathrm{~dB}$. When we have the incoherent addition of two sounds, resulting by (1) is:

$$
L=10 \log (105.7+106.7)=67.7 \mathrm{~dB}
$$

The result is almost equal to the noise level, which generates tram transport. So the noise pollution from road traffic will have no almost effect on the final value of the equivalent noise level. The phenomenon is called sound masking.

This will occur if the difference between the levels is large (almost more than $10 \mathrm{~dB}$ ), then a higher level suppress entirely the effect of the source with lower levels. On the basis of this phenomenon can be confirmed that it is effective and efficient to focus the draft measures on noise pollution of the dominant source. Noise levels in decibels are not placed with greater accuracy than one decimal place because the resolution of the sound level meter is not greater than $0.1 \mathrm{~dB}$. The resulting values are rounded to whole $\mathrm{dB}$, because the change of less than $1 \mathrm{~dB}$ will be imperceptible to an average listener.

\subsection{Recommendations}

Noise mitigation is a set of strategies to reduce noise pollution or to reduce the impact of that noise. Therefore, developing a regulation scheme for a staged process towards lownoise tram cars must be the heart of a noise abatement strategy for tramways.

But let us return back to the technical anti-noise measures used to reduce tram noise, which is closely related to the strategy of reducing noise around of tram tracks.

Summary of recommendations:

- When designing the tram line in the town peripheries should be consider the design of the track to a separate body. Location on a separate track body has operational and maintenance advantages over the line in the pavement.

- Construction of tramway permanent way should be chosen such that the reduction of noise and vibration. It is therefore appropriate to choose the construction of contactless track using an elastic rail fastening systems and make other structural adjustments, which would lead to a reduction of negative impacts on the environment.

- To limit the emission of noise and vibrations from the surface of the track structure into free space. Most of these structural modifications is performed by inserting a flexible cushioning material, usually by rubber. One of the most commonly used adjustments is filler block profile. They are made in various lengths and shapes for all types of rails and track constructions. The use of rail dampers significantly reduces the noise emissions and vibrations caused by the operation of rail transport.

- To use the construction of the permanent way with grassing.

- To apply the layer rubber mat used to improve drainage and for sound and vibration damping.

- Among the most effective noise definitely passive measures include noise barriers. An excellent architectural and functional solution from an architectural and functional is a low concrete barrier.

- The crucial and costly difficult task played by restoring the tram car fleet of operator.

- Lastly, there are the acoustic treatment of windows and facades 


\section{Conclusion}

In conclusion it can be stated that the equivalent level of noise arising from the operation of the tram line may be more than $10 \mathrm{~dB}$ higher than the equivalent noise level from the rest of noise load (cars, buses), which means that the resulting equivalent noise level (at action of the two sources at the same time) not higher become.

Recommendations for any further tramlines extensions is, to identified the dominant source of noise in the study area before designing the anti-noise measures and its follow-up noise emissions to minimized.

The preparation of the article was supported by the Scientific Grant Agency of the Ministry of Education of Slovak Republic and the Slovak Academy of Sciences under Project No.1/0477/15.

\section{References}

1. Working Group Railway Noise of the European Commission: Position Paper on the European strategies and priorities for railway noise abatement, Brussels (2003)

2. Directive 2002/49/EC relating to the assessment and management of environmental noise. Official Journal of the European Communities L 189/12 -25, 25 June (2002)

3. WHO JRC 2011, WHO European Centre for Environment and Health, Bonn Office, WHO Regional Office: Burden of disease from environmental noise Quantification of healthy life years lost in Europe; ISBN 9789289002295 (2011)

http://www.euro.who.int/_data/assets/pdf_file/0008/136466/e94888.pdf, last visit: January 3rd 2017.

4. Directorate general for internal policies policy department b: structural and cohesion policies transport and tourism reducing railway noise pollution study Brussels, (C) European Union (2012)

http://www.europarl.europa.eu/RegData/etudes/etudes/join/2012/474533/IPOLTRAN_ET(2012)474533_EN.pdf, last visit January, 30 ${ }^{\text {rd }}$, (2017)

5. WHO 2009, World Health Organization: Night noise guidelines for Europe, WHO Regional Office for Europe Scherfigsvej 8, DK-2100 Copenhagen Ø, Denmark, (2009) http://www.euro.who.int/data/assets/pdf file/0017/43316/E92845.pdf, last visit February, 13 ${ }^{\text {rd }}(2017)$

6. L. Argalášová, J. Jurkovičová, L. Ševčíková, Z. Štefániková, K. Hirošová, J. Babjaková, A. Kánovicsová, A. Filová, Applied Mechanics and Materials, 617 (2014)

7. E. Panulinová, S. Harabinová, Applied Mechanics and Materials, 617 (2014)

8. E. Panulinová, S. Harabinová, SGEM 2013, 1 (2013)

9. A. Fyhri, G.M. Aasvang, Science of the Total Environment, 408 (2010)

10. M. Liberko, Guidelines for calculation of traffic noise levels, 1 (1991)

11. J. Smutny, L. Pazdera, Insight, 46, 10 (2004)

12. A. Pultznerová, L. Ižvolt, S. Hodas, The Transportation as the Factor of the Socioeconomic Development of the Regions, 1 (2012)

13. J. Melcer, Transport and Telecommunication, 16, (2015)

14. V. Valašková, J. Melcer, G. Lajčáková, Procedia Engineering, 111 (2015) 